\title{
SUBJECTIVE WELL-BEING OF STUDENTS ATTENDING THE SPECIAL VOCATIONAL SCHOOL FOR CHILDREN WITH PHYSICAL DISABILITIES: GENDER DIFFERENCES
}

\section{${ }^{\mathrm{a}}$ PETRONELA LADECKÁ, ${ }^{\mathrm{b}} \mathrm{DAGMAR}$ NEMČEK, ${ }^{\mathrm{C}}$ TERÉZIA HARČÁRIKOVÁ}

${ }^{a}$ Comenius University, Faculty of Education, Department of Special Education, Račianska 59, 81334 Bratislava, Slovakia ${ }^{b}$ Comenius University, Faculty of Physical Education and Sports, Nábr. arm. gen. L. Svobodu 9, 81469 Bratislava, Slovakia

${ }^{c}$ Comenius University, Faculty of Education, Department of Special Education, Račianska 59, 81334 Bratislava, Slovakia email: ${ }^{a}$ petronela.ladecka@fedu.uniba.sk,

bdagmar.nemcek@uniba.sk, 'terezia.harcarikova@fedu.uniba.sk

This paper was supported by grant project VEGA No. 1/0409/19

\begin{abstract}
The aim of the paper is to identify the level of subjective well-being of students attending the Special vocational school for children with physical disabilities with consideration of their gender. The next aim is to determine the relationship between the dimensions of subjective well-being male and female students. The between the dimensions of subjective well-being male and female students. The
research group consists of 130 students attending the Special vocational school for research group consists of 130 students attending the Special vocational school for children with Physical disabilities (19.03 2.57 years). Students were divided into groups based on the gender differences ( 87 male students. 43 fenale students). We used the standardized Berne questionnaire of subjective well-being (BSW-Y) to determine the level of positive and negative dimensions. We recorded gender differences in the sample of our students. Our findings indicate that there are some differences between the genders in consideration of their state of the subjective wellbeing. The data were statistically tested by the Kolmogorov-Smirnov test used to test the normality of distribution. The Mann Whitney-U test was used to determine differences between samples. Pearson correlation coefficient was used to determine the strength of the relationship between selected variables.
\end{abstract}

Keywords: well-being, high school students, physical disability, gender differences

\section{Introduction}

Subjective well-being (SWB) encompasses a major life goal and an important tool for optimal flourishing and functioning (Carr 2004; Fredrickson 2009; Gable and Haidt 2005). SWB is consisting of high positive affect (positive moods), lower negative affect (negative moods), and high satisfaction from life (Headey and Wearing 1991). Busseri et al. (2012) showed that these components are linked to positive psychological, physical and interpersonal functioning. Pacesova et al. (2018) and lot of other authors in their studies on SWB have examined adults, whereas research on adolescents' SWB is only in its infancy (Keyes 2006; Ronen and Seeman 2007). As for gender differences most of the studies on adolescent coping did not find differences between the genders regarding actual response to traumatic events or the kinds of coping mechanisms adolescents used (Coleman and Hagell 2007). Although developmental psychologists pinpoint the fact that both age and gender are essential components to be considered in examining the adolescents' well-being. The exact way in which these demographic factors affect adolescents is not yet sufficiently clear (Casey et al. 2011; Gogtay and Thompson 2010; Steinberg 2013). Gelhaar et al. (2007) found that older children may be more affected by exposure to emotional events than younger children. The aim of our current study was to analyze the level of general SWB, SWB dimensions and compare the SWB between boys and girls with physical disabilities

\section{Research and research methods}

The research sample consisted of 130 high school students with different physical disabilities ( $19.03 \pm 2.57$ years) attending four years of study in Special vocational school for children with physical disabilities, Mokrohájska Street 1, Bratislava, Slovakia. Students were divided into groups based on the gender differences $(n=87$ male, $n=43$ female). This survey was conducted to determine the dimensions of the subjective wellbeing. We used the Berne Wellbeing questionnaire (BSW-Y) originally developed by Grob et al. (1991) and in the Slovakia standardized by Džuka (1995). The questionnaire structure consists of two main components of well-being, i.e. cognitive and emotional dimensions. The questionnaire is comprised of five dimensions which measures individual areas relating to subjective well-being. The responses to the questions and items use 6-point Likert scales. The questions are plotted on five scales of dimensions (Džuka, 1995):

Dimension 1 - positive attitude to life: which measures the habitual aspect of subjective well-being, i.e. relatively stable personal characteristics. This scale, thus represents a cognitive evaluation of one own's life contentment. At the same time, it is considered the main component of the subjective well-being of the cognitive nature. A higher score means higher general life satisfaction.

Dimension 2 - Problem awareness: which measures the negative aspect of the current subjective feeling of the individual. A higher score means higher occurrence of problems.

Dimension 3 - Physical problems and reactions: which also measures the negative aspect of subjective feeling. Together with the previous dimension. These are not considered an integral part of the subjective well-being. Nonetheless they can be an important areas for experiencing physical problems

Dimension 4 - Self-evaluation: which maps self-esteem through expressing an attitude to oneself. Person who acquires a high score on this scale has a positive attitude to himself/herself i.e. has a positive self-evaluation.

Dimension 5 - depressive mood: which registers levels of negative content of the researched individual's mind and habitual ways of experiencing of that individual. Higher score shows that habitual psychological problems are typical for this person.

The data were statistically tested by the Kolmogorov-Smirnov test used to test the normality of distribution. The Mann Whitney-U test was used to determine differences between samples. Pearson correlation coefficient was used to determine the strength of the relationship between selected variables. Effect size (Ellis, 2010) was used to determine the magnitude of the difference between groups and was calculated by using the coefficient $\mathrm{r}(\mathrm{r} \geq 0.5$ - strong relationship; $\mathrm{r} \geq 0.3-0.5$ - medium relationship; $r \geq 0.1-0.3)$.

Each participant or their legal representative was voluntary provided with written informed consent before participating in our research.

\section{Results}

Data evaluation looked at the relationship between respondent's average scores in the positive (Positive attitude to life and selfevaluation) and negative (Physical problems. Depressive mood and Problems awareness) dimensions of personal well-being into consideration of their gender.

The dimension of Positive attitude to life is made up of items which are determining the individual's view of their future, their life enjoyment, the life pleasure and the like.

Nonsignificant results were found in the dimension of positive attitude. The average score for male students was $4.22 \pm 1.05$ points, while female students scored $4.18 \pm 1.03$ points. The difference between the average scores for the sample is 0.04 points in favor of male students. These differences were nonsignificant.

The groups' results in the negative dimensions of personal wellbeing were also analyzed. The Problem awareness dimension includes items on students' concerns about people around them, their own interpersonal relationships, their work, their health, their aging, their partner and their finances. There was found a higher average score among female students 
$(2.78 \pm 1.22$ points $)$ than among male students $(2.24 \pm 1.03$ points $)$. The difference between the two groups' average results is 0.54 points, which is significant at the $5 \%$ level $(\mathrm{U}=1402 ; \mathrm{p}=0.02$; $\mathrm{r}=0.23)$. The dimension for Physical problems includes items related to somatic problems such as levels of pain, fatigue, loss of appetite, presence of illness, dizziness or heart palpitations. In this dimension female students had a higher average score $(2.07 \pm 0.69$ points). The average score for the group of male students was $1.82 \pm 0.67$ points. The difference between the two groups' average results is 0.25 points, which was statistically significant at the $5 \%$ level $(\mathrm{U}=1477 ; \mathrm{p}=0.05 ; \mathrm{r}=0.18)$.

In the Dimension of self-evaluation were reached following results. In this dimension male students achieved a higher average score $(4.34 \pm 1.24$ points) with comparison with female students $(3.93 \pm 1.44$ points). Those differences of 0.41 points were not statistically significant.

Table 1. Gender differences of SWB dimensions
The Dimension of Depressive mood is made up of items on activity levels, interest in other people, general interests and the like. Male students had higher scores $(2.57 \pm 1.06$ points $)$ in comparison of female students $(2.43 \pm 1.14$ points $)$. The difference was 0.14 points. This difference was non-statistically significant (Table 1).

\begin{tabular}{|c|c|c|c|c|c|}
\hline Dimension of wellbeing & Gender & $\operatorname{Mean} \pm$ SD & Median \pm SD & $\begin{array}{l}\text { Mann-Whitney } \\
\text { U }\end{array}$ & p-value \\
\hline \multirow{2}{*}{ Positive attitude } & boy & $4.22 \pm 1.05$ & $4.33 \pm 1.09$ & \multirow{2}{*}{1855.00} & \multirow{2}{*}{0.94} \\
\hline & girl & $4.18 \pm 1.03$ & $4.17 \pm 1.06$ & & \\
\hline \multirow{2}{*}{ Awareness of problems } & boy & $2.24 \pm 1.03$ & $2.00 \pm 1.07$ & \multirow{2}{*}{1402.00} & \multirow{2}{*}{$0.02 *$} \\
\hline & girl & $2.78 \pm 1.22$ & $2.86 \pm 1.48$ & & \\
\hline \multirow{2}{*}{ Physical problems } & boy & $1.82 \pm 0.67$ & $1.75 \pm 0.46$ & \multirow{2}{*}{1477.00} & \multirow{2}{*}{$0.05 *$} \\
\hline & girl & $2.07 \pm 0.69$ & $2.00 \pm 0.47$ & & \\
\hline \multirow{2}{*}{ Self-evaluation } & boy & $4.34 \pm 1.24$ & $4.67 \pm 1.54$ & \multirow{2}{*}{1557.50} & \multirow{2}{*}{0.12} \\
\hline & girl & $3.93 \pm 1.44$ & $3.67 \pm 2.06$ & & \\
\hline \multirow{2}{*}{ Depressive mood } & boy & $2.57 \pm 1.06$ & $2.75 \pm 1.11$ & \multirow{2}{*}{1683.00} & \multirow{2}{*}{0.35} \\
\hline & girl & $2.43 \pm 1.14$ & $2.25 \pm 1.30$ & & \\
\hline
\end{tabular}

Legend: * $\mathrm{p} \leq 0.05 ; * * \mathrm{p} \leq 0.01$

Furthermore we analyzed the relationship between the SWB dimensions in relation to gender of participating students with physical disabilities. Among male students there was a negative correlation between scores for the positive attitude and awareness of problems ( $1 \%$ statistically significant), physical problems (5\% statistically significant), self-evaluation and depressive mood (both $1 \%$ statistically significant). Another negative correlation was found in scores of physical problems and positive attitude (5\% statistically significant). A negative correlation was also between depressive mood and positive attitude, self-evaluation (1\% statistically significant). A positive correlation at the $1 \%$ significance level was found between scores in the dimension of self-evaluation and positive attitude. There is also a significant positive correlation between depressive mood and physical problems (1\% of significance level) in Table 2.

Table 2. Relationship between SWB dimensions of male students

\begin{tabular}{|c|c|c|c|c|c|}
\hline & $\begin{array}{l}\text { Positive } \\
\text { attitude }\end{array}$ & $\begin{array}{l}\text { Awareness of } \\
\text { problems }\end{array}$ & $\begin{array}{l}\text { Physical } \\
\text { problems }\end{array}$ & Self-evaluation & Depressive mood \\
\hline \multirow{2}{*}{ Positive attitude } & \multirow{2}{*}{1} & $-0.28 * *$ & $-0.27 *$ & $0.60 * *$ & $-0.48 * *$ \\
\hline & & 0.01 & 0.01 & 0.00 & 0.00 \\
\hline \multirow{2}{*}{ Awareness of problems } & $-0.28 * *$ & \multirow{2}{*}{1} & $0.44 * *$ & $-0.23^{*}$ & $0.38 * *$ \\
\hline & 0.01 & & 0.00 & 0.03 & 0.00 \\
\hline \multirow{2}{*}{ Physical problems } & $-0.27 *$ & $0.44 * *$ & \multirow{2}{*}{1} & -0.20 & $0.33 * *$ \\
\hline & 0.01 & 0.00 & & 0.07 & 0.00 \\
\hline \multirow{2}{*}{ Self-evaluation } & $0.60 * *$ & $-0.23 *$ & -0.20 & \multirow{2}{*}{1} & $-0.30 * *$ \\
\hline & 0.00 & 0.03 & 0.07 & & 0.01 \\
\hline \multirow{2}{*}{ Depressive mood } & $-0.48 * *$ & $0.38 * *$ & $0.33 * *$ & $-0.30 * *$ & \multirow{2}{*}{1} \\
\hline & 0.00 & 0.00 & 0.00 & 0.01 & \\
\hline
\end{tabular}

Legend: $* \mathrm{p} \leq 0.05 ; * * \mathrm{p} \leq 0.01$

In the sample of female students, there were several significant relationships between the dimensions. A positive correlation was found between self-evaluation and positive attitude (1\% significance level). A significant positive correlation was found between scores of depressive mood and awareness of problems, physical problems (5\% significance level). Another positive correlation was found between dimensions of physical problems and awareness of problem at $1 \%$ of the significance level (Table 3 ).

\section{Discussion and conclusion}

Carried out research probe allowed us to monitor the status of SWB among the tested group of students. Analysis of research data indicated several important facts. We can assume significant gender differences in several dimensions relating to SWB. There was significantly higher occurrence of problems and higher negative aspect of subjective feeling in female students in 
comparison with male students. We also observed statistically significant correlations between the dimension in male and female students. Our research also found a significant link between the level of Positive attitude and Self-evaluation, between Problems awareness and Physical problems in female students. In group of male students there were several significant results in relationship between measured dimensions of Problem awareness and Physical problems, between Positive attitude and Awareness of problems, Depressive mood and Self-evaluation and between the Depressive mood and Awareness of problems,

Table 3. Relationship between SWB dimensions of female students

\begin{tabular}{|c|c|c|c|c|c|}
\hline & $\begin{array}{l}\text { Positive } \\
\text { attitude }\end{array}$ & $\begin{array}{c}\text { Awareness of } \\
\text { problems }\end{array}$ & $\begin{array}{l}\text { Physical } \\
\text { problems }\end{array}$ & Self-evaluation & Depressive mood \\
\hline \multirow{2}{*}{ Positive attitude } & \multirow{2}{*}{1} & -0.06 & 0.09 & $0.64 * *$ & -0.30 \\
\hline & & 0.72 & 0.56 & 0.00 & 0.05 \\
\hline \multirow{2}{*}{ Awareness of problems } & -0.06 & \multirow{2}{*}{1} & $0.55 * *$ & -0.18 & $0.39 *$ \\
\hline & 0.72 & & 0.00 & 0.24 & 0.01 \\
\hline \multirow{2}{*}{ Physical problems } & 0.09 & $0.55 * *$ & \multirow{2}{*}{1} & -0.28 & $0.35^{*}$ \\
\hline & 0.56 & 0.00 & & 0.07 & 0.02 \\
\hline \multirow{2}{*}{ Self-evaluation } & $0.64 * *$ & -0.18 & -0.28 & \multirow{2}{*}{1} & -0.23 \\
\hline & 0.00 & 0.24 & 0.07 & & 0.14 \\
\hline \multirow{2}{*}{ Depressive mood } & -0.30 & $0.39 *$ & $0.35^{*}$ & -0.23 & \multirow{2}{*}{1} \\
\hline & 0.05 & 0.01 & 0.02 & 0.14 & \\
\hline
\end{tabular}

Legend: $* \mathrm{p} \leq 0.05 ; * * \mathrm{p} \leq 0.01$

\section{Literature:}

1. Argyle, M. and Schwarz, N.: Subjective well-being: An interdisciplinary perspective. Oxford: Pergamon Press, 1991. ISBN: 0-08-037264-3.

2. Busseri, M. et al.: Subjective temporal trajectories for subjective wellbeing. Journal of Positive Psychology, 2012. Vol. 7, No. 1, pp. 1-15. doi:10.1080/17439760.2011.565784.

3. Carr, A. Positive psychology: The science of happiness and human strength. New York: Brunner Routledge, 2004. ISBN: 158391-991-0.

4. Casey, B., Jones. J., Somerville, L. Braking and accelerating of the adolescent brain. Journal of Research on Adolescence, 2011 Vol. 21, pp. 21-33. doi:10.1111/j.15327795.2010.00712.x.

Cognition. 2010 Vol. 72, No.1, pp. 6-15. doi:10.1016/j.bandc. 2009.08.009.

5. Coleman. J., Hagell, A. Adolescence, risk and resilience: Against the odds. Chicester: Wiley, 2007. ISBN: 978-0-47002502-4.

6. Diener, E., Larsen, R.J. Temporal stability and cross. Situational consistency of cognitive. affective and behaviour responses. Journal of Personality and Social Psychology, 1984. Vol. 47., pp. 871-883.

7. Džuka, J. Faktorová analýza modifikovanej verzie Bernského dotaznika subjektivnej pohody (BDP). Československá psychologie, 1995. Vol. 39, No. 6, pp. 512-522. 8. Ellis. P.D. 2010. The Essential guide to effect sizes. New York: Cambridge University press, 2010, pp. 103-110. ISBN 978-0-521-14246-5. doi:10.1037/1089-2680.9.2.103.
Monitoring of those areas of well-being could serve as a prediction for future statement of life attitude. Similar research should be done with consideration of different attributes and disabilities. A., Wearing, A. J. Berner Fragebogen zum Wohlbefinden
9. Fredrickson, B. Positivity. New York: Crown, 2009. 277 p. ISBN: 9780307393739.

10. Gable. S. L., Haidt. J. What (and why) is positive

psychology? Review of General Psychology. 2005. Vol 9. No. 2, pp. 103-110. doi: 10.1037/1089-2680.9.2.103

11. Gelhaar, T., Seiffge-Krenke, I., Borge, A. Cicognani, E., Cunha, M., Loncaric, D. et al. Adolescent coping with everyday stressors: A seven-nation study of youth from central, eastern, southern and northern Europe. European Journal of Developmental Psychology. 2007. Vol. 4., No.2 pp.129-156. doi:10.1080/ 17405620600831564.

12. Gogtay, N., Thompson, P. Mapping gray matter development: Implications for typical development and vulnerability to psychopathology. Brain and

13. Grob.A., Luthi, R., Kaiser, F. G., Flammer, A., Mackinnon, Jugendlicher (BFW). Diagnostica. 1991. Vol 1, pp. 66-75.

14. Headey, B., Wearing, A. Subjective well being: A stocks and flows framework. In: Strack, F., Argyle, M., Schwartz, N. 'Subjective well-being, an interdisciplinary perspective', Oxford: Pergamon Press, 1991.

15. Keyes, C. L. Mental health in adolescence: Is America's youth flourishing? American Journal of Orthopsychiatry. 2006. Vol. 76., pp. 395-402. doi:10.1037/0002-9432.76.3.395.

16. Pačesová, P., Šmela, P., Kraček, S., Plevkova, J. Women's well-being, state and trait anxiety regarding their sport activity. Sport mont. 2018. Vol. 16, No. 2, pp. 33-38. doi: $10.26773 /$ smj. 180606 .

17. Ronen, T., Seeman, A. Subjective well-being of adolescents in boarding schools under threat of war. Journal of Traumatic Stress. 2007. Vol.20, No.6, pp. 1053-1062. doi:10.1002/jts.20248.

Primary Paper Section: A

Secondary Paper Section: AM 